\title{
Erratum to: Estimating the Sediment and Water Capacity in the Aswan High Dam Lake Using Remote Sensing and GIS Techniques
}

\author{
Abdelazim Negm, Mohamed Elsahabi, and Sommer Abdel-Fattah
}

A.M. Negm (ed.), The Nile River, Hdb Env Chem, DOI 10.1007/698_2016_109,

(C) Springer International Publishing AG 2016

Erratum to: Hdb Env Chem

10.1007/698_2016_109

For this chapter, the following belated corrections were received from author:

1. The paragraph "The results indicate that the method used by AHDA underestimates the sedimentation capacity by about 4\%" in Abstract section should be replaced by "The results indicate that the present approach overestimates the sedimentation capacity by about $4.3 \%$ compared to the results of the method used by AHDA".

2. The paragraph "This means that the method used by AHDA underestimated the sedimentation capacity by about 4\%." in section 5.7 Application and Comparisons should be replaced by "This means that the present approach

The updated online version for this chapter can be found under DOI 10.1007/698_2016_109
A. Negm $(\bowtie)$
Water and Water Structures Engineering Department, Faculty of Engineering, Zagazig
University, Zagazig 44519, Egypt
e-mail: amnegm85@yahoo.com; amnegm@zu.edu.eg
M. Elsahabi
Civil Engineering Department, Faculty of Engineering, Aswan University, Aswan, Egypt
e-mail: mohamed.sahabi@aswu.edu.eg
S. Abdel-Fattah
McMaster University, Hamilton, ON, Canada
e-mail: abdelfs@mcmaster.ca

A.M. Negm (ed.), The Nile River,

Hdb Env Chem, DOI 10.1007/698_2017_20,

(C) Springer International Publishing AG 2017 
overestimated the sedimentation capacity by about $4.3 \%$ compared to the method used by AHDA".

3. The paragraph "Moreover, results indicate that the method used by the AHDA, based on the complementary cross sections, underestimates the sedimentation amount by about 4\% from year 2000 to 2012" in section 6 Conclusions and Recommendations should be replaced by "Moreover, results indicate that the present approach overestimates the sedimentation capacity by about $4.3 \%$ from year 2000 to 2012 compared to the results of the method used by AHDA".

4. Reference "14. Moustafa A (2013) Predicting deposition in the Aswan high dam reservoir using a 2-D model. Ain Shams Eng J 4:143-153" in References section should be replaced by "14. Moustafa A (2013) Predicting the deposition in the Aswan high dam reservoir using a 2-D model. Ain Shams Eng J 4:143-153".

5. Reference “37. Elsahabi MA, Negm AM, Ali KA (2016) Possible correlation of 2-D velocity profiles and sediment accumulation for AHDL. In: Nineteenth International Water Technology Conference, IWTC19, Sharm ElSheikh, Egypt" in References section should be replaced by "37. Elsahabi MA, Negm AM, Ali KA (2016) Correlating the velocity profiles to the sediment profiles of the active sedimentation zone of Aswan High Dam Lake. In: Proceedings of the nineteenth international water technology conference (IWTC19), Sharm ElSheikh, 21-23 April".

We apologize for any inconvenience caused. 